\title{
Diablotexto
}

\section{Concepción Gimeno y el Álbum Ibero-Americano: Argentina como fuente para la modernización de España}

Concepción Gimeno and the Álbum Ibero-Americano: Argentina as a source for the modernization of Spain

\author{
MARTA BEATRIZ FERRARI \\ Universidad Nacional de Mar del Plata
}

\begin{abstract}
Resumen: Examinaremos aquí algunas de las Crónicas publicadas en el Álbum Ibero-Americano por la escritora española María de la Concepción Gimeno de Flaquer (Alcañiz, 1850 - Buenos Aires, 1919). En este trabajo realizaremos una aproximación a su papel de promotora cultural. Gimeno, radicada en Argentina desde 1910 (año del centenario de la Revolución de Mayo), dedicó gran parte de su vida a forjar vínculos con mujeres de diversos países de América y fue una protagonista privilegiada de este excepcional momento histórico en el que los lazos transatlánticos entre España y Argentina ocuparon la centralidad de la política de ambos países.
\end{abstract}

Palabras clave: Concepción Gimeno, España, Argentina, modernización

Abstract: In this work, we will examine some of the Chronicles published in the Álbum Ibero-Americano by the Spanish writer Concepción Gimeno de Flaquer (Alcañiz, 1850 - Buenos Aires, 1919). This is an approach to her role of cultural promoter. Gimeno, who stablished in Argentina in 1910 (centennial year of May Revolution), dedicated most of her life to forging links between women from across America and was a privileged protagonist of this exceptional historical moment in which transatlantic ties between Spain and Argentina has been at the center of both countries politics.

Key words: Concepción Gimeno, Spain, Argentina, modernization 
El siglo XVIII proclamó los derechos del hombre, el XIX ha concedido a la mujer en algunos pueblos los que aquí pedimos; el XX los otorgará.

Concepción Gimeno, Evangelios de la mujer, 1900.

Quien quiera aventurarse en el profuso panorama que ofrecen los innumerables escritos producidos a lo largo del siglo XIX español, en torno a la figura de la mujer literata, se encontrará con variadísimas tipologías discursivas que recurren a los más disímiles soportes y medios de publicación, un panorama literario saturado de todo tipo de escritos -ensayos, artículos de costumbre, prólogos, cartas, editoriales, manuales, obras de teatro, poemas y aguafuertes- que discuten el lugar social de la mujer que lee y sobre todo, de la mujer que escribe. Sin embargo, la enorme mayoría de los discursos que abordan la figura de la literata ofrecen, en términos generales, el mismo tono irónico y burlesco, y emplean un enfoque abiertamente reduccionista y descalificador ${ }^{1}$. Estos discursos hegemonizaron las publicaciones literarias del siglo XIX en torno al surgimiento de un nuevo fenómeno social producto de un incipiente cambio en las relaciones de poder, un fenómeno que da cuenta de la construcción de una nueva subjetividad, la de la mujer literata con sus consiguientes demandas y legítimas aspiraciones.

En este contexto, resulta interesante destacar la publicación de un libro excepcional, tanto por la época en que aparece como por su temática. Me refiero a la obra que el escritor Juan Pedro Criado y Domínguez publica en Madrid en 1889, titulada Literatas españolas del siglo XIX: apuntes bibliográficos, un libro que, según su autor, "se consagra á perpetuar los triunfos y los merecimientos de nuestras insignes literatas" (12). El de Criado quizá sea uno de los primeros intentos de ofrecer una verdadera "historia intelectual” femenina (22), con su aparato crítico y su apéndice biográfico y contextual en el que se incluye un listado de revistas y periódicos dirigidos por mujeres, como así también de obras escritas por hombres que tratan sobre la

\footnotetext{
${ }^{1}$ Ver Marta B. Ferrari (2020). Amazonas de las letras. Discursos de y sobre las literatas en la España del XIX. Rosario: La mar serena Ediciones.
} 
mujer². Esta "historia literaria de la mujer (en conjunto considerada)" (45) presenta una breve reseña de "las vicisitudes y estado actual de la literatura hispano-femenil en el siglo XIX" (46), a modo de introducción al catálogo de autoras y obras que le siguen.

Si bien comienza confesando que su afán de imparcialidad le dicta que no hubo en el siglo XIX español una literata de la talla de Santa Teresa de Jesús o de Sor María de Ágreda, acto seguido admite que tampoco es necesario poner la vara tan alta por haber sido éstos "seres extraordinarios" y, por ende, "inimitables modelos". El catálogo de literatas que recoge Criado y Domínguez es francamente significativo; en él figuran entre cientos de nombres los de Gertrudis Gómez de Avellaneda, Concepción Arenal, Carolina Coronado, Emilia Pardo Bazán, Rosalía de Castro, Ángela Grassi, Pilar Sinués o Josefa Massanés. El nombre de Concepción Jimeno [sic] de Flaquer aparece incluido en el apartado de las periodistas ${ }^{3}$.

En septiembre del mismo año 1889, el periodista y escritor español Manuel Ossorio y Bernard comienza a publicar en la revista madrileña La España Moderna, un minucioso Diccionario biográfico de escritoras españolas del siglo XIX, proyecto que concluiría en 1890. En su introducción contextualiza su cometido afirmando:

Desde hace largo tiempo viene debatiéndose en las sociedades modernas un tema que podría enunciarse en los términos siguientes: " $¿ E s$ un bien o un mal que la mujer se instruya, tome parte en el movimiento intelectual, y escriba?" $Y$ el debate lleva trazas de no acabar jamás. (169)

Si el siglo XVIII había asistido, impulsado por el pensamiento ilustrado, a un intenso debate en clave seria o humorística en torno a los novedosos pero

\footnotetext{
2 Criado y Domínguez releva 51 publicaciones entre revistas y periódicos "especialmente dedicados a la mujer", entre 1822 y 1888 (1889: 176-178), exceptuando las de labores. Y consigna 18 publicaciones dirigidas por escritoras españolas entre la década del 50 y la del 80 . (1889: 174-175). En el catálogo final incluye un listado de mujeres pedagogas, oradoras y traductoras, al que suma el ítem "Señoras que sin ser escritoras, figuran merecidamente en el catálogo" (1889: 192). Asimismo, incluye en el Apéndice un listado de "Pseudónimos usados por las escritoras españolas de este siglo"; de los 23 seudónimos, 7 son masculinos (1889: 172).

${ }^{3}$ Maryellen Bieder consigna un libro anterior, de 1881, el de Diego Ignacio Parada y Barreto, Escritoras y eruditas españolas. $O$ apuntes y noticias para servir a una historia del ingenio y cultura literaria de las mujeres españolas, desde los tiempos más remotos hasta nuestros días, con inclusión de diversas escritoras portuguesas e hispano-americanas (1990: 459).
} 
rotundos cambios sociales que incidían directamente en la condición femenina, a finales del siglo XIX, la existencia de mujeres ilustradas y, además, escritoras representaba en sí mismo un problema a ser debatido y la raíz del mismo se planteaba, como vemos, en términos morales y/o religiosos. Sin tomar partido personal en el asunto -"ya sea un bien, ya un mal"-, el mismo Ossorio acaba por aceptar la evidencia de los hechos: "en nuestra patria existen señoras que escriben mucho y que escriben bien" (1889: 170).

En la entrega de octubre de 1889, Ossorio dedica una entrada de su Diccionario a "Gimeno de Flaquer (Doña María de la Concepción)", y de ella destaca que se dio a conocer "en las tertulias literarias de Ayguals de Izco" (201) y como colaboradora en varios periódicos como La Mujer, El Correo de la Moda, El Ramillete, entre otros ${ }^{4}$. Y señala asimismo un dato muy singular, su faceta como empresaria, al ser la fundadora, propietaria y directora de La Ilustración de la mujer (1872) ${ }^{5}$. Por último, anota que "desde hace algunos años reside en Méjico con su esposo D. Francisco de P. Flaquer, y desde hace siete dirige en aquella capital El Álbum de la mujer: Ilustración Hispano-americana"6.

Efectivamente, María de la Concepción Gimeno (Alcañiz, Teruel 1850 Buenos Aires, 1919) fue además de periodista, conferencista, egresada de la Escuela de Maestras de Zaragoza, ensayista, cuentista, biógrafa y novelista ${ }^{7}$. El mismo Criado menciona dos novelas suyas, una publicada como folletín, Victorina o heroismo del corazón (1873), y El doctor alemán (1880), mientras que Ossorio añade en su Diccionario varias más, entre ellas Elina Durval (1878), Alardes de hombres célebres ${ }^{8}$ (1884) y Suplicio de una coqueta (1885).

\footnotetext{
${ }^{4}$ En realidad fue editora de La Mujer (Madrid: 1871-1879), periódico fundado por Faustina Sáez de Melgar.

${ }^{5}$ Criado y Domínguez señala que "fundó la magnífica revista barcelonesa llustración de la mujer, que por sus inmejorables condiciones tipográficas y artísticas, no pudiera temer entrar en lucha con otras revistas similares" (52). Bieder señala que se trata de un error y que Criado "la confunde con una revista barcelonesa posterior del mismo título" (1990: 461) (La traducción es mía).

${ }^{6}$ Gimeno se casa con el periodista y hombre de negocios catalán Francisco de Paula Flaquer y Fraise en 1879 y en 1883 el matrimonio se traslada a México.

${ }^{7}$ Su nombre completo era María de la Concepción Pilar Loreto Laura Rufina Gimeno y Gil.

${ }^{8}$ Se trata de un error de Ossorio y el título de la novela es Madres de hombres célebres.
} 
Resulta evidente que la preocupación central de la escritora aragonesa fue la cuestión femenina. Entre sus 17 ensayos, destacan los siguientes: La mujer española. Estudios acerca de su educación y de sus facultades intelectuales (1877), La mujer juzgada por una mujer (1887), En el salón y en el tocador: vida social, cortesía, arte de ser agradable, belleza moral y física, elegancia y coquetería (1899) y La mujer intelectual (1901). Del primero de estos libros procede el texto "La literata en España", en el que realiza el siguiente diagnóstico: "El hombre español le permite á la mujer ser frívola, vana, aturdida, ligera, superficial, beata y coqueta, pero no le permite ser escritora" (1877: 211). Como vemos, la beatería y la coquetería eran los únicos extremos disculpables para la mujer española: "Una mujer está autorizada para consagrar horas á la atención de sermones insustanciales de sacerdotes ignorantes, y la mayor parte del tiempo á la toilette, y no está autorizada para consagrar una hora diaria al estudio" (1877: 212). Más allá de lo provocador que resulta dicho diagnóstico puesto en boca de una moderada feminista católica como Gimeno, lo original de su ensayo es la contextualización histórica y geográfica que da a su escrito, puesto que en él hablará de la literata no en términos generales y abstractos, sino atendiendo a la particular circunstancia que debe atravesar la mujer escritora en la España del siglo XIX. Esta singularidad será de central importancia para confrontar, como veremos más adelante, su experiencia española con la Argentina ${ }^{9}$.

A partir de este diagnóstico, propio de un "país incivilizado" (1877: 224), Gimeno se encargará de desacreditar a quienes censuran y satirizan a la literata; para ella serán "escritorzuelos", "poetas de primer vuelo", "hombres en

\footnotetext{
${ }^{9}$ En estos mismos años -1880-, la Biblioteca Universal publicaba una ambiciosa Colección de los mejores autores antiguos y modernos, nacionales y extranjeros, y dedicaba un tomo a "Las escritoras españolas contemporáneas", quizá la primera antología de textos compuestos por mujeres. Un escritor anónimo redactaba la "Introducción", en la que leemos: "La animosidad que hay contra las escritoras existe sólo en España. En Francia, en Inglaterra, en Italia, en cuantas partes se dedica la mujer á la literatura, es elogiada y respetada con el cariño y la consideración con que se elogia y se respeta al que tiene mérito verdadero". Sin embargo, se encargaba rápidamente de establecer los consabidos límites: "Jamás ensalzaremos á la que pretenda ejercer algún cargo público, á la que intente usurpar sus derechos al hombre, pero sí alabaremos siempre á la mujer ilustrada, modesta y sencilla que pueda dar la primera enseñanza á sus hijos y la educación completa á sus hijas" (1880: s/p).
} 
miniatura", "criterios en embrión", "inteligencias miopes", "luces crepusculares" o "filósofos de salón." (1877: 214). Como es dable advertir, la escritora aragonesa devuelve prolijamente la crítica masculina hacia la mujer de letras y lo hace a través de múltiples estrategias retóricas tales como metáforas, antítesis, oxímoros, o del empleo eficaz de sufijos diminutivos con clara funcionalidad despectiva, hábiles recursos expresivos tendientes a desautorizar la fuente misma de la que emanan los argumentos vertidos en contra de la mujer.

A esto se suma la envidia de las propias mujeres (1877: 215), resultando la literata "un tipo raro, un ser híbrido, un ente excéntrico ó una planta exótica" (1877: 216), figuración que retoma en cierto modo "la monstruosidad repugnante" (1844: 193) de la que hablara tempranamente Gustave Deville en su artículo "Influencia de las poetisas españolas en la literatura", publicado en 1844 en la Revista de Madrid. En él, tras defender la necesaria instrucción de la mujer, el escritor francés se apresuraba a poner estrictos límites, reduciendo el campo de operaciones femenino a la vida íntima, a las nobles emociones del corazón y a la expresión de los sentimientos religiosos, y sentenciaba: "Del deseo jactancioso de suponerse con la enerjía [sic] de la virilidad al olvido de la naturaleza y de sus leyes no hay tampoco más que un grado, y las mujeres de corazón varonil son una especie de monstruosidad repugnante a todo el mundo, y despreciables á sus propios ojos" (193).

En este mismo texto, Gimeno ofrece un "Catálogo de las escritoras y artistas más reputadas españolas y extranjeras" (239-245), que reúne cientos de nombres femeninos constituyéndose en la primera nómina -estamos hablando del año 1877- con vocación de totalidad y tendiente a ofrecer un panorama lo más completo posible sobre las literatas. Un segundo aporte del ensayo es que introduce un enfoque hasta ahora ausente de las argumentaciones precedentes sobre el tema, me refiero al hecho de que, en última instancia, son las determinaciones socioeconómicas -la clase de pertenencia-, las que deciden a la hora de tener que armonizar las tareas domésticas con la tarea intelectual: 
[Entre nuestras literatas] sólo cuatro ó seis disponen de bastante fortuna para permitirse el lujo dispendioso de una modista; las restantes se hacen los trajes y repasan la ropa de la casa, porque todas ellas pertenecen a la clase media. En la aristocracia del dinero sólo existen tres o cuatro mujeres que escriben; las demás, ni cultivan las letras, ni dedican la vida al costurero. (1877: 222)

Hacia 1883 y tras una estancia en París, la pareja Gimeno-Flaquer se instala en México. Según su biógrafa, Margarita Pintos, la amistad de Concepción con la esposa del general Porfirio Díaz le allanó el camino para entrar en los círculos de poder y fundar, con ayuda estatal, El Álbum de la Mujer (2016: 17) ${ }^{10}$. Se trató de un proyecto editorial transatlántico que ponía a dialogar la cultura española y americana (en particular la mexicana) a partir de una preocupación común: el lugar de la mujer. Aurélie Vialette propone un enfoque de este Álbum desde la categoría de "alfabetización cultural cruzada" (2015: 150). Para la autora, el proyecto editorial de Gimeno supuso no solo conectar historias y culturas sino que aspiró, a través de la incorporación de retratos visuales y escritos de mujeres de ambos lados del Atlántico, a recrear una República de las Letras hispanoamericanas.

En este Álbum confluían escritoras y periodistas hispanoamericanas y españolas de la generación de Gimeno, como Carolina Coronado, Julia de Asensi o Emilia Pardo Bazán. Pero el vínculo de la escritora aragonesa con América fue intermitente y en 1890 regresa a Madrid, donde permanecerá hasta 1910, año en que visita -posiblemente por primera vez- Argentina. Durante los casi veinte años de estancia madrileña, además de su activa faceta como conferencista en el Ateneo, editó el Álbum Ibero-Americano. Ilustración semanal (1890-1909). Se trató de una revista ilustrada de entre siglos, vinculada con el hispanoamericanismo, gestada con la intención de expandir la cultura española en Iberoamérica y a la inversa. El director fue el esposo de Concepción Gimeno, Francisco de Paula Flaquer, y ella estará a cargo de la "Crónica policroma", de la "Crónica semanal", así como de una "Crónica feminista", que más tarde pasará a llamarse "Crónica femenina y feminista".

Pero el vínculo de Gimeno con América y en especial con Argentina se fue gestando desde mucho antes de su llegada al país. Ya entre 1882 y 1883 ,

\footnotetext{
${ }^{10}$ Este Álbum se editó entre 1883 y 1890.
} 
la encontramos colaborando en el Semanario de Literatura El Álbum del hogar, de Buenos Aires, con artículos de clara temática femenina ${ }^{11}$. $Y$ en su ensayo de 1904, Mujeres de raza latina, dedica un capítulo a las "Mujeres sudamericanas" demostrando un singular conocimiento de la Argentina, de su historia (el "tirano Rosas" al que denomina "el Calígula del Nuevo Mundo"), de sus escritores (José Mármol y Juana Manuela Gorriti) y de las relaciones de poder entre hombres y mujeres ${ }^{12}$ :

No existe en la República Argentina el antropocentrismo, porque la mujer, más que reina constitucional, es reina absoluta que gobierna. Si al marido le ocurre decirla "yo soy el amo" [...] ella le contesta: 'yo el ama del amo'. ¿Para qué se ha de ocupar la argentina de la evolución feminista, si las costumbres impuestas por ella la dan tanto como le pudieran conceder las favorables leyes? (1904: 193)

En este texto, Gimeno revelará su alta opinión de la mujer argentina, a la que califica como "la mujer más progresista de la América española" (1904: 194), por su osadía, por su natural inclinación a la innovación y a la toma de decisiones, pero también por su compromiso con las causas sociales -“Ella ha creado y sostiene centros de cultura para la mujer, asociaciones de protección para la infancia, refugios para los menesterosos." (1904: 194). En su libro, Gimeno opondrá tácitamente la imagen progresista y atrevida de este país nuevo a la vetustez de una España incivilizada, tan atrasada en materia de derechos civiles para la mujer, como quedó plasmado en La mujer española. Ya en la conferencia que pronunció en el Ateneo de Madrid un año antes, titulada "El problema feminista", volvía, una vez más, sobre esta cuestión:

En naciones más progresistas que la nuestra está ganando tanto terreno el feminismo, que pronto será fuerza incontrastable. Sorprende que no haya tomado parte España en ese movimiento. No existe entre nosotros ninguna agrupación que sostenga su bandera, ningún partido militante, programa alguno oficial. (1903: 78)

\footnotetext{
${ }^{11}$ Los títulos son suficientemente elocuentes: "Esposa y madre", "La mujer estudiosa", "La mujer vanidosa", "Isabel de Segura y Agustina de Aragón" y "Las mujeres en el Renacimiento Literario". Para un estudio pormenorizado de estos artículos cfr. Vicens, 2016: 216-224.

${ }^{12}$ En una crónica del 22 de diciembre de 1909 rescata varios nombres más de intelectuales argentinas: Manuela Gorriti, Mercedes Pujato Crespo, "la muy ilustrada" Elía Martínez, Emma B. de la Barra, "que transcribe costumbres bonaerenses", "la culta Delfina Mitre de Drago, que encanta con sus poemáticos acentos, lo mismo que Ana Pintos con su erudición.[...]. Novelistas distinguidas como Carlota Garrido de la Peña, [...] cultivadoras de las artes tan afortunadas como Lola Maza, María Obligado de Soto y Josefa Aguirre de Basilicós" (Gimeno, 1909a: 554).
} 
Unos años después, en marzo de 1909, Concepción Gimeno dedica una de sus crónicas del Álbum Ibero-Americano, la titulada "La mujer en la ciencia", a "Las ilustradas damas del Consejo Nacional de Mujeres de la República Argentina." Si bien volveremos sobre este tema más adelante, aquí se hace necesario abrir un breve paréntesis para referirnos al significado que dicho Consejo tuvo dentro del espectro de asociaciones femeninas en Argentina. En primer lugar, el Consejo ocupó un papel fundamental para vincular las experiencias locales con las internacionales en torno a las problemáticas feministas. En segundo lugar, los disensos internos que venían vislumbrándose ya desde los inicios, acabaron con la escisión del mismo precisamente para los festejos del Centenario. Como señala Marcela Vignoli, por un lado estaban los sectores más conservadores, "las mujeres vinculadas a tareas de beneficencia y caridad", y por otro "las que habían alcanzado títulos universitarios y que habrían representado la vertiente progresista del feminismo en Argentina" (2018: 129). Una vez más, España está ausente del concierto de países con asociaciones similares y ajena a esta red internacional consolidada en torno a la cuestión feminista.

La crónica de Gimeno comienza afirmando que "no es flor del jardín feminista la mujer científica; existió en todas épocas" (1909f: 271), y a partir de allí se dedica a historizar el papel de la mujer en la ciencia desde Hipatía, pasando por Diótima y Aspasia hasta llegar a Marie Curie. Lo que le interesa destacar a la autora es el surgimiento de una "mujer nueva", ya sea filósofa, oradora, lingüista, física, matemática, bióloga, humanista, antropóloga, pedagoga o psicóloga, una nueva subjetividad que ella antepone, incluso, al tradicional rol maternal: "No vale más la mujer que da mayor número de hijos a la Patria [...]; hoy la mujer de mérito sobresaliente es la que puede sustituir a su marido, desempeñando cargos que él desempeñara” (1909f: 272). Y de esto puede dar cuenta la propia biografía de Concepción Gimeno.

En mayo de 1909, la escritora aragonesa vuelve a escribir desde Madrid en el Álbum Ibero-Americano dos crónicas referidas a la República Argentina. Ambas hacían alusión a los próximos festejos por el centenario de la Revolución acaecida el 25 de mayo de 1810. La primera de ellas, titulada 
"Españoles y argentinos", aludía a la donación por parte de la colectividad española del monumento "A la Nación Argentina", adjudicado al escultor Agustín Querol, un símbolo en el que Gimeno leía "la unidad de raza, de espíritu y de idioma entre los naturales de la República y los españoles que residen en ella" (1909c: 218) ${ }^{13}$. Llama la atención la esmerada descripción que realiza del monumento demostrando inusuales conocimientos arquitectónicos: las dimensiones y altura del basamento, la escalinata, la piscina, los grupos escultóricos y su pormenorizada simbología.

La segunda crónica, titulada "La mujer en el Centenario de la República Argentina", anuncia los actos que organizará el Consejo Nacional de Mujeres, "importantísima Sociedad formada por 600 damas de lo más selecto, a la que pertenece la culta esposa del Presidente de la República"14 (1909c: 219). Resulta evidente que el Consejo al que se refiere Gimeno y en el que posiblemente participa con una de sus conferencias es el que quedó conformado tras la salida del grupo de mujeres universitarias en 1908, representado por el sector más conservador ${ }^{15}$.

Sin embargo, la escritora española parece estar por encima de estos disensos, tanto por su adhesión a la causa del sufragio femenino (que era,

\footnotetext{
${ }^{13}$ Dicho monumento, conocido en Argentina como "Monumento de los Españoles" y emplazado en Avenida del Libertador y Sarmiento, en la ciudad de Buenos Aires, fue inaugurado recién en 1927 por una serie de circunstancias entre las que cuenta el fallecimiento del mismo Querol poco después de la escritura de esta nota. En el número del 30 de diciembre de 1909 aparece una nota necrológica de la misma Gimeno (566). Con anterioridad, en el número del 30 de enero de 1900, el Álbum lbero-americano le dedicaba una crónica bajo el título "España en la Exposición de París".

${ }^{14}$ Se refiere a Josefa Bouquet, esposa del Presidente José Figueroa Alcorta. Según indica Gimeno, la Presidenta del Consejo fue Alvina [sic] Van Praet de Sala y las Secretarias Belén de Tezanos de Oliver y Mercedes Pujato Crespo; Elia M. Martínez era la Presidenta de la Comisión de Prensa. En 1914, ya radicada en Argentina, Gimeno vuelve a escribir una nota laudatoria del CNMA y en particular, de su Presidenta (1914: 6). Lo mismo hace con la figura de su secretaria, Mercedes Pujato Crespo (fundadora de la Asociación Nacional "Pro Patria"), a quien dedica su crónica "Iniciativas de la Mujer argentina" (1915: 8).

${ }^{15}$ Vignoli agrega que "al analizar cómo quedó la membrecía del CNMA luego de la escisión de las universitarias, vemos que de las 72 sociedades incorporadas, 55 eran benéficas y 17 perseguían fines intelectuales o artísticos", y concluye que "en la escisión de 1910 las universitarias no lograron arrastrar a otras asociaciones con ellas." (2018: 139).
} 
junto con el pacifismo, uno de los parteaguas del CNMA) como por el rescate indistinto de damas de la beneficencia y de intelectuales universitarias ${ }^{16}$ :

Distintas asociaciones docentes, que laboran por el engrandecimiento de la mujer, existen en la República Argentina. La principal de estas asociaciones es el Consejo Nacional de Mujeres, que preside la popular Alvina [sic] Van Praet de Sala, señora elegantísima, tan bellamente intelectual como hermosamente femenina. Las ciencias tienen representación femenina en la Doctora Grierson y en Ernestina y Elvira López. (1909a: 554)

En el contexto de las celebraciones del Centenario, ambas facciones terminarán organizando sus respectivos Congresos. El "oficial” se desarrolló entre el 11 y 16 de mayo de 1910, mientras que el organizado por la Asociación de Mujeres Universitarias, llamado "Primer Congreso Femenino Internacional", tuvo lugar del 18 al 23 de mayo del mismo año (Vignoli, 2018: 143). El semanario Caras y Caretas ofrece una foto en su edición del 21 de mayo teniendo a la Doctora Ernestina López como oradora central (1910a: s/p). El espíritu de dicho discurso inaugural era "establecer lazos de unión entre todas las mujeres del mundo", y en él se reclamaba "un sitio honroso para las educacionistas, redactoras de periódicos, médicas, artistas y trabajadoras"17 (Lorenzo, 2017: 156).

Por su parte, el Álbum del Centenario publica una nota titulada "Congreso del Centenario del Consejo Nacional de Mujeres" en la que se da cuenta de la celebración del mismo, una oportunidad de revelar "la preparación de la mujer de nuestro país, auspiciando su causa en forma moderada, culta y de acuerdo con su naturaleza femenina", congreso que "vendría á ser un justo tributo de la mujer de nuestros días á las patricias argentinas” (278). A Gimeno le interesa compartir con sus lectoras hispanoamericanas el sentido de este encuentro destinado a visibilizar el progreso alcanzado por el esfuerzo del normalismo de las educadoras, para lo cual reproduce el Programa completo

\footnotetext{
${ }^{16}$ En una Crónica del 30 de octubre de 1909 da a conocer los lineamientos del Congreso mundial para el sufragio femenino, destacando el papel de su vicepresidenta, Mrs. Fawcett, a quien se debe "la admisión de las mujeres en la Universidad de Cambridge" (470).

${ }^{17}$ Margarita Pintos señala respecto del Congreso: "Más de doscientas mujeres del Cono Sur discutieron asuntos tales como las leyes internacionales, los problemas matrimoniales y la igualdad salarial. Se aprobó, una resolución de apoyo al gobierno del Uruguay por aprobar la primera ley de divorcio en América Latina" (24).
} 
de las actividades previstas que van desde el análisis del papel desarrollado por la mujer en la instrucción del pueblo hasta la historización de las revistas femeninas, pasando por las funciones de la Sociedad de Beneficencia y un registro de libros escritos por mujeres, haciendo especial hincapié en el estudio de las fuentes de sostenimiento económico de dichas iniciativas ${ }^{18}$. Como ya lo había hecho en Mujeres de raza latina, Gimeno reitera aquí su elogio de la mujer argentina como auténtico factor de progreso -"su intelectualidad es admirable; perfectamente equilibrada"-, que hace extensiva a la nación toda, "una de las llamadas a más brillantes destinos." (1909c: 219) Una vez más, la escritora española ensalza el modelo de mujer argentina que es a la vez madre, maestra y salonnière, "que vive en su tiempo, que vive la vida moderna", por oposición a lo que registra en su tierra. Argentina es para Concepción Gimeno el país que ha llegado a una síntesis superadora al lograr "una civilización para los dos sexos" (1909c: 219).

En su edición del 30 de abril de 1910, el semanario Caras y Caretas de Buenos Aires publicaba una noticia bajo el título "Conferencias feministas" y la ilustraba con dos fotos de Concepción Gimeno. Allí se anunciaba la próxima llegada a la capital de la "distinguida escritora española" con el fin de dar "algunas conferencias feministas, aprovechando la oportunidad de las fiestas del centenario". (1910b: 75) Una de dichas conferencias versaría sobre la vida de la infanta doña Isabel de Borbón quien sería una huésped ilustre para las fiestas mayas. La nota de Caras y Caretas califica a Gimeno de "personalidad descollante dentro de las letras femeninas de Europa" y lo fundamenta poniendo el acento en su "refinada ilustración y su cultura exquisita" (1910b: 75). Destaca asimismo, su faceta de novelista, biógrafa y oradora (sus exposiciones en el Ateneo de Madrid con la asistencia del rey Alfonso le valieron una gran visibilidad y reconocimiento), a la vez que subraya sus trabajos eruditos y la dirección de El Álbum Ibero-Americano.

\footnotetext{
${ }^{18}$ El programa insiste claramente en la relevancia de la mujer dentro de las Instituciones benéficas. En este sentido, el punto noveno del mismo resulta altamente revelador de lo que venimos señalando: "Estudio convincente de que la acción concurrente de la mujer en el progreso no es feminismo mal entendido ni socialismo" (1909c: 218-219).
} 
Como vemos, hay evidencia suficiente de que Concepción Gimeno estuvo en Buenos Aires para los festejos del Centenario y participó de ellos públicamente. Sin embargo, la Unión Ibero-Americana de junio de 1911, al dar cuenta del éxito que la escritora española estaba alcanzando en Argentina transcribe una nota laudatoria del diario La Prensa en la que se afirma:

[R]ealizóse ayer la Asamblea de socias del Consejo Nacional de Mujeres. El salón resultó estrecho para dar cabida á la numerosa concurrencia de damas que fué atraída por el anuncio de que hablaría por primera vez en Buenos Aires la literata española señora Concepción Gimeno de Flaquer. (22)

Ya instalada en Argentina, entre 1913 y 1915 Concepción Gimeno seguirá colaborando en publicaciones españolas como la recién mencionada Revista de la Unión Ibero-Americana de Madrid, cuya finalidad era la de estrechar relaciones sociales, económicas, científicas, literarias y artísticas entre España, Portugal y las naciones americanas ${ }^{19}$. En estas crónicas, dará cuenta de la obra de algún poeta argentino -es el caso de Carlos López Rocha, en el número de marzo de 1913-, o bien de la "psicología de las calles bonaerenses", donde leemos en clave moderna una descripción del "Pandemonium" de la Avenida de Mayo por oposición a la calle de los paseantes ociosos, la de la Florida:

La muy animada Avenida de Mayo dice al viajero que se halla en una ciudad mercantil, de tráfico acelerado; en una ciudad ardiente, luminosa; aquel bullir y rebullir de los transeúntes, aquel nervioso correr, aquella febril agitación de enjambre, aquel estridente ensordecedor ruido á nada comparable, aquel oleaje carnal ofrece la visión de la mayor heterogeneidad étnica, aquel flujo y reflujo con su subir y bajar de marea viva, los empuja, los arroba. (1913:18)

El contexto en el que Concepción Gimeno hace su primera aparición pública en Buenos Aires coincide, como vemos, con los múltiples festejos del Centenario del 25 de mayo de 1810. Los lazos entre España y su ex colonia se vuelven un tema de referencia obligada tanto dentro como fuera del país. En este sentido, resultan de sumo interés los testimonios de dos altas figuras de la política española del momento. Me refiero, en primer lugar a Gumersindo de

\footnotetext{
${ }^{19}$ La Unión Ibero-Americana fue creada en Madrid en 1885 y la revista del mismo nombre comenzó a publicarse en 1887. Concepción Gimeno perteneció, junto con otras escritoras del momento, a la sección de Señoras de la UIA y en 1906 fue nombrada Presidenta. http://dbe.rah.es/biografias/13368/maria-de-la-concepcion-gimeno-de-flaquer
} 
Azcárate, diputado republicano, muy afín al krausismo ${ }^{20}$ y uno de los fundadores de la Institución Libre de Enseñanza, quien se refiere a la necesidad de que las repúblicas hispanoamericanas se encaminen "al establecimiento de una federación espiritual, que sirva á la cultura y al progreso de la humanidad" (s/a, 1910a: s/p). Y en similar sentido se expresaba también el presidente del congreso de los diputados, el conservador Eduardo Dato cuando declaraba:

\begin{abstract}
Rotos los antiguos lazos materiales que unían á Europa con América, la obra civilizadora y progresiva del tiempo ha formado otros vínculos más fuertes [...]. Por eso irá España á la Argentina á celebrar sus progresos, á contribuir á la grandeza de esa hermosa fiesta de la paz y del trabajo, y cuando se junten las banderas de ambas naciones más que el abrazo de dos pueblos esa unión ha de simbolizar para argentinos y españoles la íntima compenetración de dos almas. (s/a, 1910a: s/p)
\end{abstract}

Concepción Gimeno, que dedicó gran parte de su vida a forjar vínculos con mujeres de diversos países de América -Margarita Pintos afirma que recorrió doce países latinoamericanos de la mano de asociaciones feministas y de sus contactos con logias masónicas (2016: 11)-, fue una protagonista privilegiada de este excepcional momento histórico en el que los lazos transatlánticos entre España y Argentina ocuparon la centralidad de la política de ambos países. Su lucha por aunar los esfuerzos de las mujeres españolas y americanas (su retórica de la hermandad femenina) se nos presenta hoy como una suerte de réplica oportuna de la tan declamada fraternidad entre los pueblos, cimentada -como lo escribe en una de sus crónicas de junio de 1909en la "unidad étnica, la afinidad de espíritus y la identidad de ideales" (1909d: 242). América surge en el pensamiento de Gimeno como fuente para la modernización de España, en un intercambio guiado por un anhelo regenerador, paralelo al deseo de regeneración social de la mujer: "La España moderna [...] resurge en América", dirá en otra de sus crónicas de abril de 1909

\footnotetext{
${ }^{20}$ Solange Hibbs-Lissorgues emparenta el pensamiento de la propia Gimeno con los principios filosóficos del krausismo: fe en la perfectibilidad del hombre, fe en el progreso individual y colectivo, sólo alcanzable mediante la educación y el pleno desarrollo de la razón (2010: s/p).
} 
(1909e: 170) ${ }^{21}$. Y dentro de América, Argentina será evaluada como un "emporio de civilización" (1909b: 326).

Si bien Concepción Gimeno fue una figura reconocida por sus contemporáneos -Juan Tomás Salvany afirma en 1895 que las ediciones de sus obras se agotaban rápidamente (10)-, con el paso de los años su nombre se fue diluyendo hasta caer en el olvido como muchas otras escritoras y periodistas de su época. Maryellen Bieder propone algunas razones para explicar este olvido; la estudiosa norteamericana sostiene que estas escritoras nunca tuvieron asegurado un lugar en la memoria colectiva de la historia literaria española, y sugiere posibles causas, por una parte, el hecho de que su audiencia fuera predominantemente femenina y por otra, el carácter convencional de gran parte de sus escritos, cuando no "su manifiesto didactismo moral" o "el dominio persistente del sentimentalismo postromántico..." (1990: 459) (La traducción es mía).

Pero quizá la paradoja final esté cifrada en el mismo acto jurídico que registra su muerte. Francisco de Paula Flaquer fallece en Buenos Aires un año antes que su esposa, y la noticia de la muerte de Concepción Gimeno, acaecida el 11 de abril de 1919, es recogida tanto por periódicos argentinos como españoles. El diario argentino La Prensa publica dos esquelas: una del Consejo Nacional de Mujeres y sus Comisiones (Biblioteca, Prensa y Propaganda, Ayuda Social y Oficina de Informaciones), y otra conjunta del Patronato Español y la Sociedad Cultural Española ${ }^{22}$. El periódico madrileño La Época toma la noticia de la prensa argentina y comunica la noticia a sus lectores recién el día viernes 6 de junio de 1919: "Ha fallecido en Buenos Aires

\footnotetext{
${ }^{21}$ En la misma crónica da cuenta del encargo de un cuadro cuyo motivo era la Fundación de Buenos Aires al pintor español Moreno Carbonero, con el fin de ser colocado en el Ayuntamiento de la ciudad el 25 de mayo de 1910. El lienzo, en palabras de Gimeno, sabrá expresar "el heroico espíritu de la raza" (1909e: 170).

${ }^{22}$ Esta Sociedad, también conocida como "Institución Cultural Española", fue fundada en 1912 por el médico cántabro Avelino Práxedes Gutiérrez, quien invitó a intelectuales y científicos españoles a impartir cátedras y cursos en la Argentina a través de la Junta para Ampliación de Estudios. Así, visitaron Argentina, Ramón Menéndez Pidal (1914), José Ortega y Gasset (1916), Eugenio D'Ors, Salvador de Madariaga, Francisco Ayala o Gregorio Marañón, entre otros. Bajo los auspicios de esta Institución se creó en 1923 el Instituto de Filología de la Universidad de Buenos Aires, que tuvo como primer director a Américo Castro y, a partir de 1927, a Amado Alonso.
} 
la notable escritora española doña Concepción Gimeno de Flaquer. Su vocación de propagandista la llevó á América hace algunos años." (s/a 1919a: 4). Sin embargo, su partida de defunción, que notifica lugar, fecha, hora y causa de su muerte, así como lugar de entierro -el Cementerio del Oeste, más conocido como Cementerio de la Chacarita-, estado civil -viuda- y nacionalidad -española-, deja un espacio en blanco al declarar su profesión.

Por paradójico que resulte, María de la Concepción Gimeno, que fue maestra, ensayista, novelista, cuentista, biógrafa, crítica literaria ${ }^{23}$, periodista, oradora, empresaria editorial y actriz de teatro, no logró ser reconocida civilmente por ninguna de sus múltiples actividades. No lo fue en Argentina "esa hermosa Nación sudamericana"- como ella caracterizaba a su país de adopción, y tampoco lo fue en su momento en su propia tierra. Efectivamente, Margarita Pintos consigna los datos de un censo realizado en Madrid en el año 1878, en el que se menciona a los moradores permanentes del piso principal del $N^{\circ} 14$ de la calle de la Florida: María Francisca Gil, de estado civil viuda como cabeza de familia, sus tres hijos y una sirvienta. Solo Máximo, el hijo varón, aparece con una profesión, la de estudiante. Concepción, de 28 años y que para la fecha había publicado dos novelas, un ensayo, y era editora de un periódico y colaboradora de varios más, aparecía premonitoriamente sin ninguna profesión reconocida.

\footnotetext{
${ }^{23}$ Esta faceta de su producción, bastante menos estudiada que sus abordajes feministas, resulta igualmente digna de tenerse en cuenta, aunque más no sea por la virulencia de sus aseveraciones. Transcribo un pasaje en el que ella, que rendía un auténtico culto al realismo, se pronuncia contra las estéticas finiseculares: "¿Qué han inventado los parnasianos simbolistas, naturalistas, estetas, decadentistas y modernistas? El simbolismo hállase en la Biblia, que es metafórica representativa; el parnasianismo en antiguos perfeccionadores de la forma, con vacuidades del fondo; el modernismo en los románticos, rebeldes a las reglas retóricas; el naturalismo en las páginas cervantinas; el decadentismo no es más que nueva florescencia del culteranismo, del preciosismo francés, del gongorismo español. Los estetas no pretenden que la palabra exprese la idea; bástales que la palabra tenga autonía [sic], aroma, colorido; abusan de las voces inusitadas, inauditas. Los decadentistas no cultivan la psicología, sino la patología. Los decadentistas son demoledores, anarquistas literarios; su pensamiento no es suyo; es el de Byron, el de Leopardi, el de Vanini. En los llamados satanismos encuéntrase el virus de Carducci, de Baudelaire, de Verlaine, con menos gracia, con menos belleza" (1915: 7).
} 


\section{BiBLIOGRAFÍA}

BIANCHI, Marina (2007). "Los artículos «a lo femenino» de María de la Concepción Gimeno de Flaquer". En Margherite Bernard, Luisa Chierichetti, María Mercedes González de Sande, Ivana Rota (eds.), Papel de mujeres. Mujeres de papel. Periodismo y comunicación del siglo XIX a nuestros días. Bergamo: Sestante edizioni, pp. 21-51.

BIEDER, Maryellen (1990). "Femenine Discourse - Feminist Discourse: Concepción Gimeno de Flaquer", Romance Quarterly, vol. 37, n. ${ }^{\circ} 4$, pp. 459-477. <http://www.cervantesvirtual.com/obra/femenine-discoursefeminist-discourse-concepcion-gimeno-de-flaquer-971303/> [Fecha de consulta: 20 de diciembre de 2019].

Centenario Argentino. Álbum historiográfico de Ciencias, Artes, Industria, Comercio, Ganadería y Agricultura (1911). Buenos Aires: Cabral, Font y Cía.

Criado y Domínguez, Juan Pedro (1889). Literatas españolas del siglo XIX: apuntes bibliográficos. Madrid: Establecimiento Tipográfico de D. Antonio Pérez Dubrull.

DeVILLE, Gustave (1844). "La influencia de las poetisas españolas en la literatura". En Revista de Madrid, Tomo II. Madrid: Imprenta de la sociedad literaria y tipográfica, pp. 190-199.

FERRARI, Marta B. (2020). Amazonas de las letras. Discursos de y sobre las literatas en la España del XIX. Rosario: La mar serena Ediciones.

Gimeno de FlaQUeR, Concepción (1915). "Iniciativas de la mujer argentina. La Asociación «Pro Patria» y su fundadora", Unión Ibero-Americana, enero de 1915, pp. 8-9.

Gimeno de FlaQUeR, Concepción (1914). "Vida intelectual argentina. El Consejo Nacional de Mujeres de Buenos Aires y su Presidenta", Unión IberoAmericana, 28 de febrero de 1914, pp. 6-8.

Gimeno DE FlaqueR, Concepción (1913). "Psicología de las calles bonaerenses", Unión Ibero-Americana, marzo de 1913, pp. 18-21.

Gimeno de Flaquer, Concepción (1909a). "Actividad intelectual de las damas argentinas, Álbum Ibero-Americano, 22 de diciembre de 1909, p. 554.

Gimeno de Flaquer, Concepción (1909b). "Arte Español en Buenos Aires", Álbum Ibero-Americano, 30 de julio de 1909, p. 326.

Gimeno de Flaquer, Concepción (1909c). "La Mujer”, Álbum Ibero-Americano, 22 de mayo de 1909, p. 219.

Gimeno DE FlaqueR, Concepción (1909d). "En la unión Ibero-Americana", Álbum Ibero-Americano, 7 de mayo de 1909, p. 234.

Gimeno de Flaquer, Concepción (1909e). "Actual españolismo en América", Album Ibero-Americano, 22 de abril de 1909, p. 170.

Gimeno de FlaQUer, Concepción (1909f). "La mujer en la ciencia”, Álbum IberoAmericano, 30 de marzo de 1909, pp. 271-272.

Gimeno de FlaqueR, Concepción (1904). Mujeres de raza latina. Madrid: Imp. del Asilo de Huérfanos del S.C. de Jesús.

Gimeno de Flaquer, Concepción (1903). El problema feminista. Madrid: Imp. del Asilo de Huérfanos del S.C. de Jesús. 
Gimeno de FlaqueR, Concepción (1877). La mujer española. Estudios acerca de su educación y de sus facultades intelectuales. Madrid: Imp. y Librería de Miguel Guijarro.

HIBBS-LISSORGUES, Solange (2010). "Itinerario de una filósofa y creadora del siglo XIX: Concepción Jimeno de Flaquer". $<$ http://www.cervantesvirtual.com/nd/ark:/59851/bmcg73z0> [Fecha de consulta: 16 de enero de 2020].

LORENZO, María Fernanda (2017). Que sepa coser, que sepa bordar, que sepa abrir la puerta para ir a la Universidad. Las académicas en la Universidad de Buenos Aires en la primera mitad del siglo XX. Buenos Aires: EUDEBA.

OsSORIO Y BeRnARD, Manuel (1889-1890). Apuntes para un diccionario de escritoras españolas del siglo XIX. Madrid: La España Moderna, septiembre de 1889 y mayo de 1990.

PINTOS, Margarita (2016). "Concepción Gimeno: feminista poliédrica", Filanderas. Revista interdisciplinar de estudios feministas, 1, pp. 7-26.

s/a (1919a). "Muerte de Concepción Gimeno de Flaquer", La Época, 6 de junio de 1919 , p. 4.

s/a (1919b). "Muerte de Concepción Gimeno de Flaquer", La Prensa, 12 de abril de 1919, p. 17.

s/a (1911). "La señora Gimeno de Flaquer en América". Unión IberoAmericana, junio de 1911, pp. 21-22.

s/a (1910a). "Congreso de Mujeres", en Caras y Caretas. Buenos Aires, 21 de mayo de $1910, \mathrm{~s} / \mathrm{p}$.

s/a (1910b). "Conferencias feministas", en Caras y Caretas. Buenos Aires, 30 de abril de 1910, p. 75.

s/a (1880). "Las escritoras españolas contemporáneas", en Colección de los mejores autores antiguos y modernos, nacionales y extranjeros. Tomo LVIII. Madrid: Litografía e imprenta de la Biblioteca Universal, en $<$ https://archive.org/stream/AMont10733/AMont10733_djvu.txt> [Fecha de consulta: 12 de diciembre de 2019].

Salvany, Juan Tomás (1895). "Biografía". En Concepción Gimeno de Flaquer, Madres de hombres célebres, Madrid: Tipografía de Alfredo Alonso, pp. 7-14.

ViALETTE, Aurélie (2015). "Vidas paralelas e historias conectadas: Concepción Gimeno de Flaquer (1850-1919) y sus redes transatlánticas". En Pura Fernández (ed.), No hay nación para este sexo. La re(d)pública transatlántica de las letras: escritoras españolas y latinoamericanas (1824-1936). Madrid y Frankfurt, Iberoamericana-Vervuert, pp. 147-166.

VICENS, María (2016). La escritora hispanoamericana en la cultura argentina de entresiglos. Filodigital. Repositorio institucional de la Facultad de Filosofía y Letras de la Universidad de Buenos Aires. $<$ http://dspace5.filo.uba.ar/bitstream/handle/filodigital/6142/uba_ffyl_t_20 16_90574.pdf?sequence $=1$ \&isAllowed $=y>$

[Fecha de consulta: 16 de diciembre de 2019]. 
VIGNOLI, Marcela (2018). "El Consejo Nacional de la Mujer en Argentina y su dimensión internacional, 1900-1910", Travesía, vol. 20, n. ${ }^{\circ} 2$, pp. 121147.

Fecha de recepción: 29 de julio de 2020.

Fecha de aceptación: 24 de noviembre de 2020. 